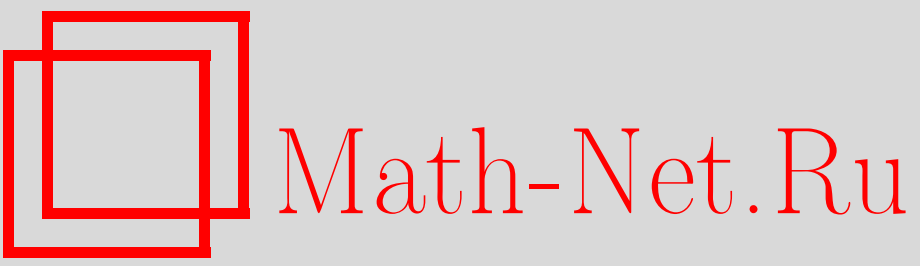

А. Ю. Голубков, Первичный радикал присоединенной группы Шевалле над ассоциативным кольцом, УМH, 2001, том 56, выпуск 4, 143-144

DOI: https://doi.org/10.4213/rm424

Использование Общероссийского математического портала Math-Net.Ru подразумевает, что вы прочитали и согласны с пользовательским соглашением

http://www.mathnet.ru/rus/agreement

Параметры загрузки:

IP: 54.84 .234 .179

26 апреля 2023 г., 14:40:50 


\title{
ПЕРВИЧНЫЙ РАДИКАЛ ПРИСОЕДИНЕННОЙ ГРУППЫ ШЕВАЛЛЕ НАД АССОЦИАТИВНЫМ КОЛЬЦОМ
}

\author{
А. Ю. ГолуБков
}

1. Введение. В настоящей работе получена характеризация первичного радикала для расширений элементарной группы Шевалле, построенной при помощи присоединенного представления конечномерной простой алгебры Ли над ассоциативным колцом с единицей. Доказанная формула служит естественным обобщением теоремы о первичном радикале для афффиной схемњ Шевалле-Демазюра над коммутативным кольцом из работы [1].

\section{2. Основные результаты.}

ОПределЕниЕ 1 . Нормальная подгруппа $A$ группы $G$ называется перв ичной, если в факторгруппе $G / A$ централизатор каждой неединичной нормалњной подгруппы тривиален. Пересечение $\operatorname{rad}(G)$ всех первичных нормальных подгрупп группы $G$ назьвается первичныц $р а д и$ калом группы $G$. Будем говорить, что группа $G$ обладает разрешимым радикалом, если в $G$ существует максимальная нормальная разрешимая подгруппа.

Пусть $R$ - ассоциативное кольцо с 1 и первичньм радикалом $\operatorname{Rad}(R), \mathfrak{G}_{\mathbb{C}}$ - конечномерная полупростая алгебра Ли с базисом Шевалле

$$
\left\{X_{\alpha}, H_{i}\right\}_{\alpha \in \Sigma, 1 \leqslant i \leqslant l}
$$

где $\Sigma$ - система корней алгебры $\mathfrak{G}, \operatorname{rk}(\Sigma)=l, \pi$ - точное представление алгебры $\mathfrak{G}$ на конечномерном векторном пространстве $V, M=V_{\mathbb{Z}}$ - решетка векторов в $V$, инвариантная относително действия всех $\pi\left(X_{\alpha}\right)^{m} / m !, \alpha \in \Sigma, m \geqslant 0$. В частности, для присоединенного представления $\pi=\operatorname{ad}$ в качестве $M$ можно взять $\mathbb{Z}$-решетку, порожденную базисом Шевалле алгебры $\mathfrak{G}$.

ОПредЕлЕниЕ 2. Для каждого $r \in R$ и $\alpha \in \Sigma$ определим автоморфизм $x_{\alpha}(r)$ абелевой группы $R \otimes_{\mathbb{Z}} M$, полагая

$$
x_{\alpha}(r)=\sum_{n=0}^{\infty} r^{n} \pi\left(X_{\alpha}^{n} / n !\right)=\exp \left(r \pi\left(X_{\alpha}\right)\right),
$$

где

$$
r^{n} \pi\left(X_{\alpha}^{n} / n !\right): t \otimes v \mapsto\left(t r^{n}\right) \otimes \pi\left(X_{\alpha}^{n} / n !\right)(v)=\left(t r^{n}\right) \otimes v \pi\left(X_{\alpha}^{n} / n !\right)
$$

для любых $t \in R, v \in M, n \geqslant 0$. Группа $E_{\pi}(\Sigma, R)$, порожденная всеми $x_{\alpha}(r), \alpha \in \Sigma, r \in R$, называется әлементарной группой Шевалле типа $\Sigma$ над колњцом $R$ (см. [2], [3]).

Tеорема 1. Пусть $R$ - ассоциативное кольцо с $1,1 / 2$ и 1/3, $\mathfrak{G}_{\mathbb{C}}-$ простая алгебра

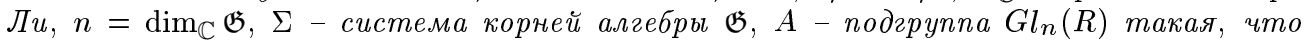
$E_{\text {ad }}(\Sigma, R) \subseteq A$. Предположим, что $1 /(l+1) \in R$ для $A_{l \geqslant 4}$ u $1 / 5 \in R$ для $G_{2}$. Тогда

$$
\operatorname{rad}(A)=A \cap C_{n}(R, \operatorname{Rad}(R))=\left\{a \in A \mid a b-b a \in M_{n}(\operatorname{Rad}(R)), b \in M_{n}(R)\right\} .
$$

СлеДСтвиЕ 1. Пусть $R$ - кольцо с полиномиальным тождеством, $1,1 / 2$ и 1/3, $\mathfrak{G}_{\mathbb{C}}$ - простая алгебра Ли типа $G_{2}$. Тогда

$$
\operatorname{rad}\left(E_{\text {ad }}\left(G_{2}, R\right)\right)=E_{\text {ad }}\left(G_{2}, R\right) \cap C_{14}(R, \operatorname{Rad}(R)) .
$$

СлЕДСтвиЕ 2. Пусть $R$ - ассочиативная алгебра с 1 над полем рачиональных чисел, $\mathfrak{G}_{\mathbb{C}}-$ простая алгебра $Л и, n=\operatorname{dim}_{\mathbb{C}} \mathfrak{G}, \Sigma-$ система корней алгебры $\mathfrak{G}$. Тогда группа $A$ такая, что $E_{\text {ad }}(\Sigma, R) \subseteq A \subseteq G l_{n}(R)$, обладает разрешимым радикалом в том и только том случае, когда первичный радикал $\operatorname{Rad}(R)$ алгебры $R$ нильпотентен. 


\section{СПИСОК ЛИТЕРАТУРЫ}

[1] А. Ю. Голубков // УМН. 2000. Т. 55. № 3. С. 173-174. [2] C. Chevalley // Séminaire Bourbaki (1960/61). V. 13. Exp. 219. Paris, 1961. [3] Р. Стейнберг. Лекции о группах Шевалле. М.: Мир, 1975.

Московский государственньй университет им. М. В. Ломоносова

E-mail: golubkov@mccme.ru
Принято редколлегией 01.06 .2001 